\title{
The Nature of Deviant Behaviour Patterns that are Prevevalent among Pupils in Secondary Schools in Zambia: A Case of Central Province
}

\author{
${ }^{1}$ Dr. Martin Banda, PhD, ${ }^{2}$ Godfrey Mweemba
}

\begin{abstract}
In the past four decade, there has been increasing concern about the behaviours that children exhibit in schools (particularly secondary schools). Teachers frequently complain that they spend more time trying to control pupils than teaching them. Administrators are concerned about problems ranging from chronic truancy to assaults on teachers. Drug abuse, bullying, smoking, , promiscuity, aggressive and disruptive behaviour, absconding from classes, drunkenness, stealing, careless school work and other offences against the school rules and regulations had been reported to be rampant and on the increase. School administrators, teachers and parents had been concerned about the frequent lack of respect for authority and the apparent lack of discipline in schools.
\end{abstract}

Keywords: Deviant, deviance, norms, primary deviance, secondary deviance.

Deviance is behaviour that some people in society find offensive and which excites, or would excite, if it were discovered, disapproval, punishment, condemnation, or hostility. Deviance is behaviour that is likely to get you into trouble. Deviant behaviour is outside the bounds of the group or society (Goode, 1997:37).

Many times during a day we disagree with people, but we don't usually label those we disagree with as deviant. Deviance is not simply behaviour. It involves a moral judgment. Deviance involves a judgment made by somebody. Actually, any act can be defined as deviant (Henslin, 1999:192).

Deviance is said to be a relative term. It is not possible to isolate certain acts and find them universally condemned by all societies as deviant acts (Not even murder or incest). Even within a given society, behaviour defined as deviant continually undergoes redefinition. Deviance, furthermore, is relative to time and place. It is not possible to find something that is absolutely condemned by all societies. (Kornblum: 1988) further states that, behaviour that is deviant in one society may not be in another. Even within one society, what is deviant today may not be deviant tomorrow. Two examples that highlight the relative nature of deviance are provided below:

(A). Is killing wrong? Usually it is. But, is murder wrong when it is done in self-defense or in warfare? Vietnam veterans were taught to be efficient killers for war, but could not control themselves when reintroduced into civilian life.

(B).What about the case of Nelson Mandela? For years, the ruling party in South Africa viewed him as a "dangerous political deviant." To most South Africans, those who are Black, Mandela is a revered leader of the freedom movement (Kornblum, 1988:201).

Heslin (1999) states that, the community defines deviance. People, as they interact, define what is appropriate and what is not. Some people in the community have more power than other to define deviance. People who occupy high positions within economic religious and political sectors are in a better position to determine what laws are enacted and to enforce their definitions of deviance.

The upper class is in a better position to determine what crimes are seen as serious and they tend to point to problems associated with the lower classes. Organizations with financial backing are better equipped to present its impressions of deviance.

Dysfunctional Deviance

Functionalists (Goode, 1997) like to concern themselves with those forms of deviance that assist in maintaining the social order. Dysfunctional deviance would be those types of deviance that threaten the social order. Some forms of political deviance might be considered here. 


\section{Dr. Martin Banda \& Godfrey Mweemba}

Primary Deviance which refers to the act of breaking a rule and secondary Deviance

Henslin (2004) notes that sometimes people become more deviant as a result of being labelled as deviant. This happens because the label becomes a part of the person's self-concept.

Secondary deviance is the process that occurs when a person who has been labeled a deviant accepts that new identity and continues the deviant behaviour (Kendall, 1998:196).

According to Henslin (2004:146), labels open and close doors. Once a person is labelled as deviant, often that person is forced to have almost exclusive contact with other deviants

The structural-functionalist approach to deviance argues that deviant behaviour plays an important role in society for several reasons. First, deviance helps distinguish between what is acceptable behaviour, and what is not. In a sense deviance is required in order for people to know what they can and cannot do. It draws lines and demarcates boundaries. This is an important function as it affirms the cultural values and norms of a society for the members of that society. In addition to clarifying the moral boundaries of society, deviant behaviour can also promote social unity, but it does so at the expense of the deviant individuals, who are obviously excluded from the sense of unity derived from differentiating the non-deviant from the deviants. Finally, and quite out of character for the structuralfunctionalist approach, deviance is actually seen as one means for society to change over time. Deviant behaviour can imbalance societal equilibrium. In the process of returning societal equilibrium, society is often forced to change. Thus, deviant behaviour serves several important functions in society.

As explained in the proceeding paragraphs, deviance can vary quite dramatically from culture to culture. Cultural norms which are relative; this makes deviant behaviour relative as well. For instance, in general certain societies it is uncommon for people to restrict their speech to certain hours of the day. In the Christ Desert Monastery, there are specific rules about when the residents can and cannot speak, including a specific ban on speaking between 7:30 pm and 4:00 am. The norms and rules of the Christ Desert Monastery are examples of how norms are relative to cultures.

Current research on deviance by sociologists takes many forms. For example, Karen Halnon of Pennsylvania State University studies how some people exercise informal deviance. Her research focuses on what she calls "deviance vacations," where people of certain socioeconomic status descend to lower strata. For instance, heterosexual white males may become drag queens on the weekend. It is a vacation because heterosexual white males can afford to descend temporarily and then return to the advantages of their true socioeconomic status. Other examples include white hip-hop acts like Eminem and Nu-Metal bands like Limp Bizkit that mimic lower or middle class people in order to use their socioeconomic credentials for profit, despite their true socioeconomic status. It is the remit of sociologists and criminologists to study how these norms are created; how they change overtime; and how they are enforced.

In every society there are some norms and values that each member of a particular community is expected to adhere to. Conformity to such norms and values brings about cohesion among the members of the particular community. However, spontaneity in every society is likely to arise due to reluctance or problematic behaviours among few members of the society. To such there are some prescribed penalties that act as remedying factors to help deter the perpetuation of such unwanted behaviours.

A school is said to be a community within the larger community. Schools always embark on orderliness and thorough discipline. However, just like people differ in their personalities so are their characters and this makes it quite hard for school authorities to produce uniform behaviour among pupils. The enactment of rules and regulations is meant to help govern the welfare of the school and maintain certain acceptable sanity. However, spontaneity acts among pupils cannot be dispensed of completely, because of the varying backgrounds from where the pupils are drawn, hence the need of formulating stringent rules and regulations other remedial therapies that can help to bring sanity in the school.

\section{A Note on Deviant Behaviour in the Zambian Schools}

In Zambia, Simate (1992) reported that indiscipline in schools included vandalism, strikes, bullying, smoking, drug abuse, promiscuity, aggressive and disruptive behavior, absconding from classes, drunkenness, stealing, careless school work and other offences against the school rules and regulations. 
Banja (1999), Whitehead (1993), Simate (1993), Nwana (1971) also conducted their research on indiscipline in schools though each study identified different independent variables as the basis of their study. For instance Simate (1993) cited parental occupation, family size among others as factors that contributed to indiscipline in schools. Whereas Banja (1999) brought forward psychological factors such as cognitive levels and personality traits as factors that contributed to indiscipline in schools. Nwana (1971) mentioned disorganization of the family and the disregard of social mores by society in general and pupils in particular. Whitehead (1993) cited aggressive behaviours especially among boys, coming from single parents' homes.

The study endeavoured to find out the nature of deviant behaviours patterns that are prevalent among pupils in secondary schools in Zambia

(a) To find out the nature of deviant behaviours most prevalent among pupils and the levels to which they escalate.

\section{RESEARCH QUESTION}

1. What is the nature of the deviant behaviours most prevalent among pupils and to what levels do they escalate?

\section{THEORETICAL FRAMEWORK}

Control Theory. All motivational theories assume people are good and require special circumstances to make them bad. A popular type of constraint theory assumes people are bad and require special circumstances to make them good. For, according to Control theory, the rewards of deviance are many. The control theory holds that the rewards of deviance are ample. Therefore, nearly everyone would engage in deviance if they could get away with it. The degree to which people are prevented from violating norms and laws accounts for variations in the level of deviance (Brym, Lie 2003:168). Sociologists have applied control theory to gender differences in crime. They have shown that girls are less likely to engage in delinquency than boys because families typically exert more control over girls, supervising them more closely and socializing them to avoid risk. Sociologists have also applied control theory to different stages of life. Just as weak controls exercised by family and school are important in explaining why some adolescents engage in deviant or criminal acts (Brym, Lie 2003:160). Labeling and control theories have little to say about why people regard certain kinds of activities as deviant in the first place. For the answer to that question, we must turn to conflict theory, a third type of constraint theory (Brym, Lie2003:160).

\section{Most Prevalent Deviant Behaviours among Pupils in Zambia and the Leading FACTORS}

On June 30, 2008 in the nation of Zambia the issue of teacher-student sexual abuse and sexual assault was brought to the attention of the High Court of Zambia where a landmark case decision, with presiding Judge Philip Musonda, awarded \$45million Zambian Kwacha $(\$ 13,000$ USD) to the plaintiff, a 13 years old girl-student for sexual abuse and rape by her school teacher. This claim was brought against her teacher as a "person of authority" who, as Judge Musonda stated, "had a moral superiority (responsibility) over his students" at the time.

Simate (1992)reported that indiscipline in schools included vandalism, strikes, bullying, smoking, drug abuse, promiscuity, aggressive and disruptive behavior, absconding from classes, drunkenness, stealing, careless school work and other offences against the school rules and regulations.

Wesang'ula e tal (2010) states that, violence is not a new phenomenon in the modern educational system. It is manifested in the form of rioting, sexual violence, fighting and bullying. The purpose of this study is to establish teachers' and students' perceptions of psychological factors contributing to violent behavior among public secondary school students in the western province of Kenya. The study was based on the social learning theory by Albert Bandura and a descriptive survey research design was adopted. The study population was composed of 638 principals, 6,354 teachers and 65,969 form two students. Stratified random sampling technique was used to select students from 213 secondary schools, while purposive sampling technique was used to select teachers Questionnaires and in-depth interview guide was used to collect data from the respondents and a pilot study was carried out to establish the reliability and validity of the data collection instruments. However, qualitative data were transcribed and reported according to emerging themes, while quantitative data were analyzed using 
descriptive statistics such as frequency counts, means and percentages. As such, inferential statistics such as t-test and Mann-Whitney $U$ test were applied. The findings of the study indicated that forms of violence in schools included: sexual violence, rioting, bullying and fighting, while the perceived psychological factors contributing to violent behavior were: anxiety problems, ethnic violence, mental problems and fear of being punished. Generally, analysis of the problem revealed that students, regardless of their gender and/or type of school they attended, perceived causes of violence alike. Recommendations of the study were that: guidance and counseling should be reinforced in schools, students with mental and psychological disorders should be referred to medical doctors and psychiatrists, ban on caning of students should be encouraged, proper communication channels ought to be established in order to maintain a tranquil environment in schools and ranking of schools by Kenya National Examination council should be abolished.

Other cases included riotous behaviour in schools by Shana (1974) that secondary schools and other high institutions of learning were used by nationalists in their struggle for independence. Under Moab psychology pupils staged various protests and rebellious acts in order to force the government to respond to their demands. This form of riotous behaviour continued especially in boarding secondary schools were pupils would act violent when they are subjected to poor diets. Such riotous trends have continued even in the present period.

\section{Methodology}

The study used survey method as research design to effectively collect both qualitative and quantitative data from the respondents. According to Sidhu (2006) a survey usually involves collecting data by interviewing a sample of people selected to accurately represent the population under study. Survey questions concern people's behaviour, their attitudes, how and where they live, and information about their backgrounds. Therefore the study opted to use this method taking into account the nature of the research at hand. The researcher used both qualitative and quantitative paradigms to gather necessary information from the participants. Focused group discussions with pupils were also conducted to seek further clarity on certain responses from the pupils that seemed to be unclear and also to consolidate the entire work by exploring pupils 'views further.

\section{Nature of Deviant Behaviour Prevalent in Schools}

Pupils were asked to list the nature of deviant behaviours that were prevalent in their schools.

Figures below shows their responses. Mukobeko and Kabwe recorded high rates under category 3 with counts of 11 and 15 pupils respectively out of the total number of 25 respondents for each school. Kalonga recorded high rates under category 2 and Bwacha recorded high rates under category 1 with counts of 15 and 19 pupils respectively out of the total number of 25 respondents for each school. Despite the varying levels of prevalence the study showed that all three natures of deviant behaviours depicted below were prevalent in all the schools under this study.

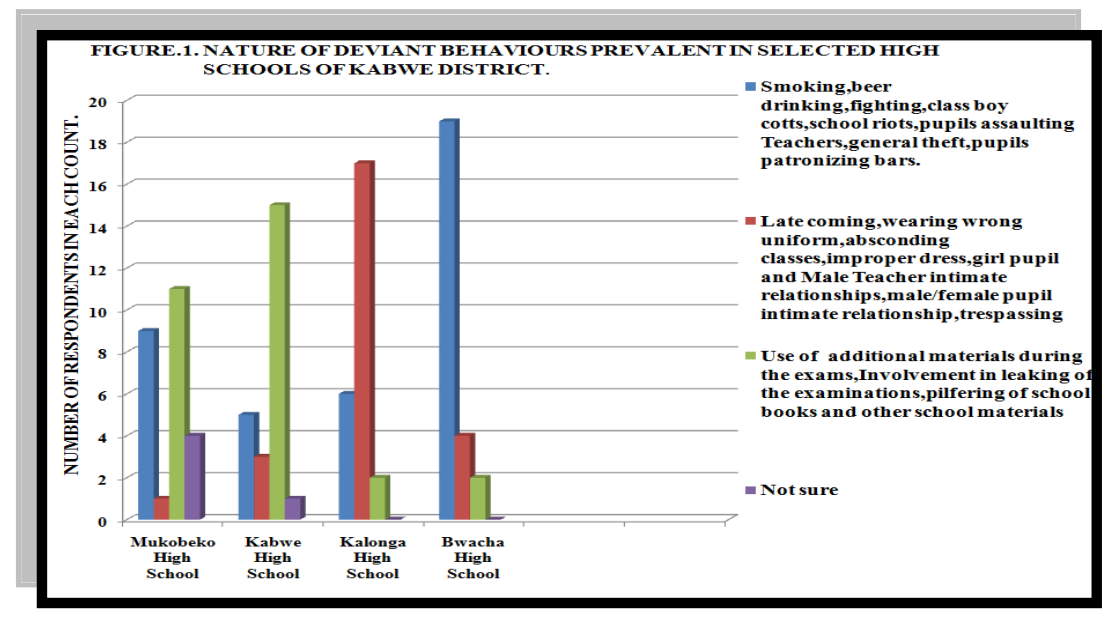

\section{DiSCUSSIONS}

The study revealed that there were quite numerous types of deviant behaviours prevalent among the pupils in the high schools under study. The following categories of deviant behaviours were confirmed as being prevalent. Category 1. Smoking, beer-drinking, fighting, class boycotts, school 
riots, general theft, pupils patronizing bars. Mukobeko rated 36\%, Kabwe rated 20\%, Kalonga rated $24 \%$ and Bwacha $76 \%$.Bwacha had the highest percentage in this category. Category 2. Included, Late coming, wearing wrong attires, absconding classes, girl- male teacher intimate relationship, girl-boy intimate relationships, trespassing, and they were rated as follows, Mukobeko 4\%,Kabwe $12 \%$,Kalonga $68 \%$ and Bwacha $16 \%$.Kalonga recorded the highest score. Category 3, included, Use of additional materials during examinations, involvement in leakage of examination papers, pilfering of school books, and these were rated as Mukobeko 44\%, Kabwe 60\%, and Kalonga 8\%, and Bwacha $16 \%$ Kalonga recorded the highest score again in this category. Other types of deviant behaviours that were prevalent in the above schools at varying rates were, Paint graffiti at $51 \%$ for all schools, Dropping of subject $48 \%$, Rudeness to prefect, Kissing between male and female pupils, Pupils jumping over wall fences, Shunning preventive maintenance, were all rated at $46 \%$, Use of abusive language 53\%,Not participating in compulsory school programmes, Breaking school properties, Missing lessons, Wearing wrong attires, Coming with cell phone to school, refusing to be supervised by class monitors and prefects, were all rated at 54\%,Nick naming of pupils and teachers $72 \%$, Gang activities among pupils 28\%.Despite recording varying levels of deviance prevalence the study revealed that types of deviant behaviours that prevailed in the above mentioned schools common and wide spread.

\section{NATURE OF THE SCHOOL ENVIRONMENT}

Another essential realm of life, where the socialization of children takes place, is the school. The present study indicates that the child, who comes to school with problem conditioned by the family, will have problems at school too. These school children are, primarily, making little progress at school, breaking discipline and absence from school. The school is supposed to provide an enabling learning environment for all classes of pupils. The emphasis on law and order is meant to create somewhat uniform and acceptable behavioural trends among the pupils. During the interview in the study of Estonian girls the fact was ascertained that the child's adaptation difficulties, or risk of adaptation difficulties, certainly become obvious at school. It means that if a child has some kind of problems, then those will be clearly expressed at school. Here the need arises to work out at school such programmes and forms of work as can help pupils to solve their adaptation problems. It is remarkable that the behaviour of this contingent depends so strongly, firstly, on the mood of the moment, secondly, on particular people and thirdly upon circumstances.

Rules and regulations are meant to direct pupils' behaviour to the generally acceptable norms of the school. Alas the situation tends to different due to the volatile environment that tends to emerge in the school. The school environment is greatly marred by the creation of rules and regulations that are negatively stated and created without the full participation of the pupils or any of their representatives.

Dollar (1972:43) states that, Elementary student has two main areas in which he must learn to function: the school and the home... The teacher as an agent of reinforcement and punishment can glue together these two areas for many children. The teacher's ability to influence parental attitudes toward the school and the child's level of academic achievement have direct consequences for helping the student modify his behaviour in the class room and at home.

The above role of the teacher cannot be over emphasized. It is incumbent for teachers to create an enabling environment for the pupils. In a focused group discussion pupils narrated how some teachers set bad precedence. At Kalonga high school one pupil narrated an incident where two male pupils (a prefect and a non-prefect) were caught up in the same syndicate of kissing and romancing with their mates. The non-prefect was given severe punishment while the prefect was let scotch free. This showed an element of segregation and disfavour to the non-prefect pupil who in the due course might question the validity of the school rules. Matza $(1969: 93,157)$ gives us the most vivid and graphic account of the process of adopting a deviant role. He says, "The acts of authorities in outlawing a proscribed behavior can have two effects, keeping most out of the behavior, but also offering new opportunities for creating deviant identities."

Dollar (1972) elucidates further that, a negatively stated rule, like punishment, fails to communicate appropriate behaviour. Negative statements specify behaviour that is wrong but fail to provide clues to correct behaviour. Even if rules are liable to be bent this was not supposed to be done at the conspicuous expense and disadvantage of those not in power. Some teachers also set very bad precedence by not adhering to the tenets of their ethics in as far as social behaviours was concerned. 
MOE(1997.p.51) states in part that, "Indiscipline among teachers constituted, Teachers' involvement in immoral activities with school pupils..."Asked on whether intimate relationships between male teachers and female pupils had any impact on the increase of misconducts among pupils, $94 \%$ of the teachers responded in the affirmative indicating that this trend was very prominent. Pupils at Kalonga cited an incident where two teachers collided to one girl. The girl later reported to the administrators that she was impregnated and the two teachers have since been discharged from the Ministry of Education. Such matters were serious in that they contributed to bringing down the already degraded status of the teachers in Zambia. Also pupils at Kabwe high school cited an incidence where two male teachers took two girls for a drink up and the girls came back to join their friends in the school hall where the school held a variety party. It did not take long before their colleagues discovered that the two girls were drunk. They were thus brought to book by the administrators along side with the teachers. This study in an interview with the Head teachers revealed that most schools do not prescribe the nature of punishment to be meted for each rule that pupils abrogated. Most of the existing rules had not been revised for a long time and so they tended to be inappropriate. Sociologist

The study also revealed that in schools there were these seemingly conflicting rules and regulations. Pupils in the focused group discussions explained that at their school they have no tack shop and the vendors who sell food stuffs are usually outside the school fence and yet the pupils are restricted from going outside the school fence. Girls also contended that they are not allowed to plait their hair on Mondays but on other days they are allowed to do so and so they questioned this gesture. There were also told not to fold their stockings because they attracted male teachers. The boys also on the same matter argued that why should they restrict them from wearing any other colours of stockings when they wear long trousers that make what they are wearing inconspicuous. The same goes with what pupils called inappropriate policies by ministry of education for example the re-entry policy has not been implemented as it is supposed to be. Hence it said to be producing mothers instead of pupils.

\section{Social Control Systems Present in Schools}

Perry Nelson in the news letter entitled Addressing Barriers to Learning stated that in their effort to deal with deviant and devious behaviours and create safe environments, schools increasingly have adopted social control practices. These include some discipline and classroom management practices that analysts see as "blaming the victim" and modeling behaviour that fosters rather than that counters development of negative values. Perry further explains that, too many school personnel see punishment as the only recourse in dealing with a student's behaviour. As revealed in the study this had been the trend in schools that were surveyed. An overview insight that was obtained from teachers as to whether administering of stiffer punishment or corporal punishment to deviant pupils would help curb these behaviours showed $88 \%$ of the teachers were of the view the abolition of corporal had impacted negatively in that it had increased the rate of misconducts among pupils. The social control systems that were applied in schools left much to be desired. For instance most the forms of punishment that were administered in schools were either less reformative or not reformative at all. In the focused group discussion most pupils indicated that the punishments that they were usually given were not reformative.

Teachers use the most potent negative consequences available to them in a desperate effort to control an individual and to make it clear that acting in such a fashion is not tolerated. Essentially, short of suspending the individual from school, such punishment took the form of a decision to do something to the student that he or she does not want done. In addition, a demand for future compliance usually is made along with threats of harsher punishment if compliance was not forth coming.

Bandura and Walters (1963:194) states that, the effects of physical punishment are probably complex and highly dependent upon the intensity of the punishment and the manner in which it is administered. A parent who attempts to modify his child's behaviour by inflicting severe physical punishments is providing an aggressive model from whom the child may learn aggressive means of responding in interpersonal situations. Although because of fear of retaliation, the child may not counter aggress in his parents' presence, he may never the less model his behaviour after that of his parents when he himself wishes to cope with or control the behaviour of others.

Researchers discovered that mothers who forced compliance with their demands through the use of power-assertive disciplinary techniques, which included verbal and physical aggression, had children who exhibited aggressive power-assertiveness in controlling the behaviour of peers and resisted the 
influence attempts of both teachers and peers. In contrast, one aspect of the use of reasoning as a disciplinary technique may be that the parent provides an example of how to respond nonaggressive in frustrating social interactions.

\section{Conclusion}

The study revealed clearly that there were no reports of fatal forms of deviance in schools such as use of fire arms by pupils to disrupt classes or fuel anarchy in the schools as is the case in most foreign schools that were reviewed. Most of the deviant acts that were prevalent either hinged on pupils' common delinquency or adolescent perpetrated acts of truancy. There were very few and rare cases of deviance based on typical pupil nuisance.

However, this does not mean that such cases did not exist. The school system indeed displayed a lot of gaps in as far as the modeling of pupils' behaviours was concerned. The non stocking of detailed profile of individual pupils' personal bio-data indeed made teachers and administrators look to be aliens in the sight of the pupils that had been entrusted to them for safe custody as loco-parentis on behalf of the government. Teachers were often caught off guard as regards the emerging trends of their pupils' behaviours. Most teachers neither had sufficient background information on their pupils that could help provide corrective measures (in times of need) to errant pupils nor do they have models to which they could direct their pupils to emulate good behavioural trends. Their vital role as confidants has over time lost its savour in that most them had fallen victims of immoral activities with the pupils they were supposed to guide.

The study further revealed that acts of vandalism were not very much pronounced except in situations where pupils rioted or ran amok. Beer drinking was however, very prevalent. Both girls and boys had habits of going in hide out places where they freely imbibed the common small sachets beers called Tujirijiri in the local language as they played pool tables. These hide outs have certain special names such as Bafana bafana or Muchibwendo (in the ditch). Bar owners despite displaying the rule stating that, 'no one under 18 years should be allowed in the bar,' never did anything to prohibit these pupils from patronising their premises. Most of the time these pupils were in fact clad in their school uniform as if it was an emblem to show that society and elders no longer had enough teeth to bite. The social mores even in the larger society had been lowered in that society itself seem to have run out of proper models to which younger ones could look. Younger girls were engaging into indiscriminating immoral activities with older men from both higher and lower statuses in their bid to fulfill their life pleasures as if they were acting in response to Solomon's word that says, "Enjoy your life whilst you are still young and the sun is still at noon or rather before it sets and before the olden days come when you will say I am too old to do this and that." The pieces of advice from adults could no longer be heeded by the younger ones. Disrespect and unleashing of volatile insults characterises most communities this in turn spilled into the school being a sub set of the larger community. The levels at which most of these deviant acts escalated were not beyond teachers' and administrators control. They were within manageable limits only if prompt and appropriate measures were to be implemented to the letter. All stake holders in the school needed to be versed with the predisposing factors to antisocial behaviours. Parents needed to play their ardent role in helping modeling their children characters.

The study further observed that most of the deviant acts are perpetrated by the weak social control systems. For example most the schools have no properly enshrined school rules and regulations that have even the code of conduct and the penalties to each prescribed offence attached. Most pupils took this fragmentation and inconsistence in the administering of punishments as a loop hole and a stepping stone to even commit more acts. There was greater need for schools to regularly review the school rules and regulations to avoid causing conflicting acts among pupils that turn into deviance. For example most pupils wondered why schools discouraged pupils from buying the same make of the uniform attire from second hand clothing shops but rather made it mandatory for every pupil to purchase such from school. The pupils argued that most salaula materials were durable and fancy unlike what they were offered to buy in the school. Perhaps the looming plan of having schools fall under Local government and authorities would help to curb the growing trend of pupils patronizing bars. The council and state police demonstrated this when they went on an exercise caught up many pupils in the bars. This phenomenon is not new. In the recent past the late third republican President Dr. Levy Patrick Mwanawasa imposed a ban on what outgoing school leavers called end of school 
bash. This was a haven of a lot of immoral activities. Once such an incidence in the copper belt ended up into a stampede and which resulted into several pupils losing their lives. Surprising enough some of them were not even in examination classes others were grade nines, so they just went there to have fun. There is need for the Ministry of General Education to restock school with enough recreational amenities if such trends are to be arrested.

\section{REFERENCES}

[1] Goode, E. Deviant Behaviour (5 ${ }^{\text {th }}$ Ed) Upper Saddle River: NJ. Prentice Hall: 1997.

[2] Henslin, J.M Sociology: A Down-To-Earth Approach, $\left(4^{\text {rd }}\right.$ Ed) Boston: Allyn and Bacon: 1999.

[3] Henslin, J M. Sociology: A Down-To-Earth Approach, $\left(4^{\text {rd }}\right.$ Ed) Boston: Allyn and Bacon: 1999.

[4] Goode, E Deviant Behaviour ( $5^{\text {th }}$ Ed) Upper Saddle River, NJ. Prentice Hall: 1997.

[5] Goode, E (1997) Deviant Behaviour (5 ${ }^{\text {th }}$ Ed) Upper Saddle River, NJ. Prentice Hall: 1997.

[6] Henslin, James M. Sociology: A Down-To-Earth Approach, $\left(4^{\text {rd }}\right.$ Ed) Boston: Allyn and Bacon: 1999.

[7] Simate. An Investigation into the Relationship between Home Background and Indiscipline among Secondary School Pupils in Selected Zambian Schools: (Unpublished) M.Ed Thesis. UNZA: 1993

[8] Banja, M.K. The relationship between School, Environment and Indiscipline Among Pupils in Selected Government High Schools in Kitwe District: (Un published) M.Ed.UNZA: 2001

[9] Simate, F. An Investigation into The Relationship Between Home Background and Indiscipline Among Secondary School Pupils in Selected Zambian Schools (Unpublished) M.Ed Thesis. UNZA: 1993.

[10] Nwana, O.C. School Discipline in the East-Central State of Nigeria after the Civil War in West Africa; West African Journal of Education Vol.1.XIX, No.3pp 172-200: 1971.

[11] Shana, S. A Survey of Student Discipline Problems in Lusaka Secondary Schools From 1960-1970. (Unpublished) M.Ed Thesis UNZA: 1974.

[12] Dollar B. Humanizing Class room Discipline; A Behavioral Approach; New York; Harper and Row, Publishers: 1972

[13] Matza, D. On Becoming Deviant. Englewood Cliffs, NJ: Prentice Hall: 1969

[14] Dollar B. Humanizing Class room Discipline; A Behavioral Approach; New York; Harper and Row, Publishers: 1972

[15] MOE (1997) Standards and Evaluation Guidelines, Lusaka.

[16] Bandura Albert and Walters .H. Richard Social Learning and Personality Development; Holt, Rinehart and Winston, Inc. New York: 1963.

\section{AUTHORS' BIOGRAPHY}

Martin Banda is a Lecturer for Sociology and is currently the Head of Department of Educational Psychology and Sociology in the School of Education at Kwame Nkrumah University-Zambia. He holds $\mathrm{PhD}$ and MA:Ed in Sociology of Education from the University of Zambia, a Bachelor of Arts in Education (Catholic University of Eastern Africa-Nairobi). His main research interests are in Sociology of Education, Education and Society, Education Change and Pedagogical Transformation, HIV/AIDS, Sex Education and Curriculum Studies.

Mr. Mweemba Godfrey holds a Diploma, Bachelors, and Masters of Education from the University of Zambia. His major interests is the School and the community 